\title{
A PRÁTICA FEMININA NA PINTURA ERÓTICA JAPONESA PRÉ-MODERNA
}

\author{
Madalena Natsuko Hashimoto Cordaro
}

RESUMO: O presente artigo visa a mostrar alguns resultados sobre uma investigação em andamento acerca da representação da prática sexual feminina, em particular sobre a utilização de implementos substitutivos do falo masculino. Uma produção notável de afrodisíacos e objetos de prazer foi desenvolvida durante o período Edo (1603-1868), e sua representação nas pinturas e xilogravuras em folhas soltas ou em livros ilustrados encontra-se amalgamada em vários ambientes sociais e diferentes épocas históricas. A representação da masturbação feminina, embora seja mais numerosa em locais aos quais se veda o acesso masculino, também aparece nos centros das áreas de prazeres, onde, a priori, não deveriam faltar clientes e, surpreendentemente, também nos lares comuns de citadinos. Apresentar-se-ão algumas imagens selecionadas, retiradas de séries de obras de vários pintores do assim chamado ukiyo-e, no gênero shunga, "pintura-primavera", com respectivas leituras traduzidas de seus textos inseridos, desde a estampa xilográfica em preto-ebranco, até a multicolorida.

Palavras-chave: período Edo, pintura e estampa erótica japonesa, brinquedos para adultos, masturbação, implementos afrodisíacos.

\begin{abstract}
The present article aims to show a few results on an ongoing investigation about female sex performance representations, particularly on the male phallus substitutive implements usage. A great production of aphrodisiacs and pleasure objects was developed throughout Edo period (1603-1868), and its representations in paintings, prints and illustrated books are shown in a variety of historical times and social surroundings. Female masturbation representation, although more noticeable in places to which male access was limited, also shows itself in the pleasure quarters, where one would think would lack no clients and, surprisingly, also in common townsmen homes. Some selected images will be presented, taken from some painters of the so called genre of ukiyoe shunga, "spring painting", with its respective inserted texts translations, from the black and white to the multicolored print.
\end{abstract}

Key words: Edo period, erotic painting and print, adult toys, masturbation, aphrodisiac implements. 
Consta que a primeira aparição na literatura japonesa de um "consolo de viúva" ou dildo (pênis artificial) [harigata ou harikata 張形] foi em obra de Ihara Saikaku: Kôshoku Ichidai Otoko 好色一代男 (O homem que se deu ao amor), de 1682, no capítulo “Kawatta mono wa otokogeisei” 替つた物は男傾城 (“Coisa diferente mesmo é um homem desmorona-castelo""1). A protagonista do espisódio é uma mulher que trabalha na área privativa de uma grande casa de daimio [大奥 ôoku], como é comum em muitas pinturas e livros eróticos.

De fato, uma fantasia muito presente nas representações eróticas lingüísticas ou visuais envolve damas e empregadas das casas de samurais, pois se supõe que a ausência de homens estimularia a secura amorosa e a luxúria, o que equivaleria à abstinência de monjas e sacerdotisas, ou de moças em escolas femininas, ou de mulheres enclausuradas em um harém, ou de viúvas. Muitas imagens mostram também refinadas damas vestidas à moda do período Heian em seus entretenimentos solitários, como se vê em obras de Moronobu e Sukenobu.

Também nos livros eróticos as empregadas de casas de samurais [okujoch $\hat{u}$ 奥女中] são representadas com seus consolos, uma variedade de modelos e modos de utilização, sob uma ótima bem humorada e até cômica.

A pesquisadora Tanaka Yuko aponta que a iniciativa para a realização sexual, na literatura do período Edo, a começar por Thara Saikaku, parte das mulheres. E, para elas, o inimigo dos homens é o consolo, que as satisfaz plenamente, com tamanhos e espessuras a gosto. "São as mulheres que escolhem, compram e usam os consolos, são as mulheres que escolhem, convidam e utilizam a seu bel prazer os homens" (Tanaka, 2004, p.15).

O consolo é objeto fim de masturbação para as mulheres, obviamente, o que demonstra a criação de artefatos para a satisfação de seu desejo sexual. Entretanto, ao torná-lo objeto de estudo, Tanaka quer mostrar que, para o Ocidente, a primeira representação de uma mulher a se masturbar dá-se somente no início do século XX, por Gustav Klimt (mas que não se excetue Egon Schiele), enquanto que, no Japão, já no século XVII há um intenso comércio nesta área.

$\mathrm{O}$ contato com as idéias cristãs, entre outras, levou à criação de vários vocábulos novos no Japão. É interessante notar que, quando posteriormente a China se "moderniza", toma de empréstimo um léxico numeroso dessa intensa época de "tradução" para os ideogramas. Assim se passou com o termo "amor" [ren ai 恋愛]. Até então somente existia no Japão o amor koi 恋, que incluía de modo acentuado o sexo e suas paixões decorrentes. Outro conceito importante que se introduz no período Meiji (1868-1912) é o da relação entre um homem e uma mulher, sagrada, platônica e indissolúvel, que aliena o sexo para a clandestinidade. Gueixas [芸者

1. No período Edo, trata-se de uma das categorias das mulheres que ganham a vida com suas artes de entretenimento. $O$ termo é derivado da tradição, originalmente com o sentido de ser uma mulher "tão bela que pode até levar um grande senhor de castelo à ruína". A sátira de Saikaku é dirigida a um cruzamento de gêneros: o homem também será objeto de compra e venda e seus clientes serão de ambos os sexos. 
“mulheres das artes"], cortesãs [yûjo 遊女 “mulheres dos entretenimentos"] e amantes sustentadas financeiramente [mekake 妾] passam a ser discriminadas (Tanaka, 2004, p.18) embora não exterminadas.

Atenta Tanaka Yuko que não se sabe com precisão quando se iniciou e a partir de quando se difundiram os consolos no Japão. Sabe-se que já existiam no fim do período Heian e que no início do Edo já estavam bastante difundidos. No início da pintura erótica ukiyo-e, meados do século XVII, existiam em grande número; em meados do XVIII, escasseiam e renascem, de forma um pouco diferenciada, nos anos 1820 (Tanaka, 2004, p.20).

Embora tenha se tornado bastante acessivel nos anos 1770, os consolos não se tornaram populares entre as mulheres citadinas, pois como aponta Tanaka "além de seus altos preços, havia muitos homens que podiam aproximar-se livremente delas" (p.21).

Diz-se que o exemplo mais antigo de consolo, chamado Orisbós, provém da célebre, porém pouco conhecida, ilha de Lesbos, na antiga Grécia, para ser usado por duas mulheres e não para masturbação solitária. Sabe-se também de sua presença nos haréns da Arábia e na antiga Roma, de onde se transmitiu à Inglaterra nos anos de 1660. Na China, era chamado de kagu 仮具, "objeto substituto", e utilizado nas alas femininas dos palácios imperiais. Supõe-se, portanto, que a introdução no Japão se tenha dado através da China. Na Antigüidade, eram feitos de pedra ou madeira e utilizados nos festivais de fertilidade em oferendas aos deuses e, no período Nara, começa-se a utilizar os chifres de bois ou búfalos. Em sua parte oca, colocava-se tecido empapado em água quente que o tornava mais macio e inchado, fazendo-o assemelhar-se a seu sucedâneo, e era utilizado para consolos solitários. No período Edo, pululam desenhos e materiais, e também utilizações mais variadas.

Sugiyama Shigeru aponta 1716 como a data provável de fundação de Yotsumeya 四目屋 ${ }^{2}$, que tinha filiais em Edo, Osaka e Kyoto, como loja especializada em afrodisíacos e parafernália sexual, pois é a partir daí que os consolos e uma série de afrodisíacos começam a ser conhecidos amplamente, mas sabe-se que já em 1626 havia vendas de chômeigan 長命丸, "remédio para vida longa", pomada vendida como receita secreta para a fruição dos prazeres eróticos. A associação de chômeigan 長命丸 e de variedade de incensos como fortalecedor do apetite sexual era promovido conscientemente pela Yotsumeya como "coisas estrangeiras", particularmente holandesas, o que lhes acrescentava status privilegiado exótico.

Na obra (Keichû kibun) Makura bunko (傾注紀文)枕文庫 “(Histórias memoráveis) A Biblioteca do Travesseiro", de 1822, com ilustrações de Keisai Eisen e texto de Tamenaga Shunsui (1790-1843), existe uma receita de chômeigan: cravos (chôji 丁子), ópio (ahen 阿片), derivado de arsênio (hiso 吪素), tipo de cânfora

2. Em Edo, localizava-se em Yagenbori no distrito de Ryôgokubashi (atual Higashi Nihonbashi itchôme), mas havia também filiais em Ôsaka e Kyôto. 
importada de Bornéus (ryûnô 竜脳) e uma essência retirada de veado asiático. Sua utilização consistia em esfregar no corpo do pênis, desde a parte baixa das glândulas até a raiz, e deveria ser lavado após o intercurso.

Embora se vendessem na Yotsumeya produtos bem genéricos como os incensos afrodisíacos (rarenkô ラ恋香, “incenso de clímax holandês”; Oranda keikô オランダ馨香, “incenso fragrante holandês”; karasenkô 唐線香 ou tôsenkô 唐線香, “incenso chinês"), havia também os mais específicos: kujiri 久志里: pequeno falo para mulheres para cobrir o dedo indicador como auxiliar na masturbação; rinnotama 鈴玉: duas bolas inseridas na vagina antes da penetração penial; yoroigata 鎧形: "capa de pênis". ou literalmente "forma de armadura", tubo perfurado colocado sobre o pênis como uma armadura como diz o nome, para ajudar a ereção e aumentar o tamanho; higozuiki 肥後芋茥, fio seco de caule de batata de lótus (arum maculatum), que se amarra em volta do pênis para proporcionar grande prazer à mulher; rinnowa 鈴輪, anel com bolinhas que rolam, para ser posicionada bem abaixo das glandes do pênis; consolo de utilização dupla (tagaigata 互形), para ser usado por duas mulheres simultaneamente; imitação de vulva (azumagata 吾妻 形), para masturbação masculina. Um painel amplo pode ser visto em estampa de Katsushika Hokusai ${ }^{3}$.

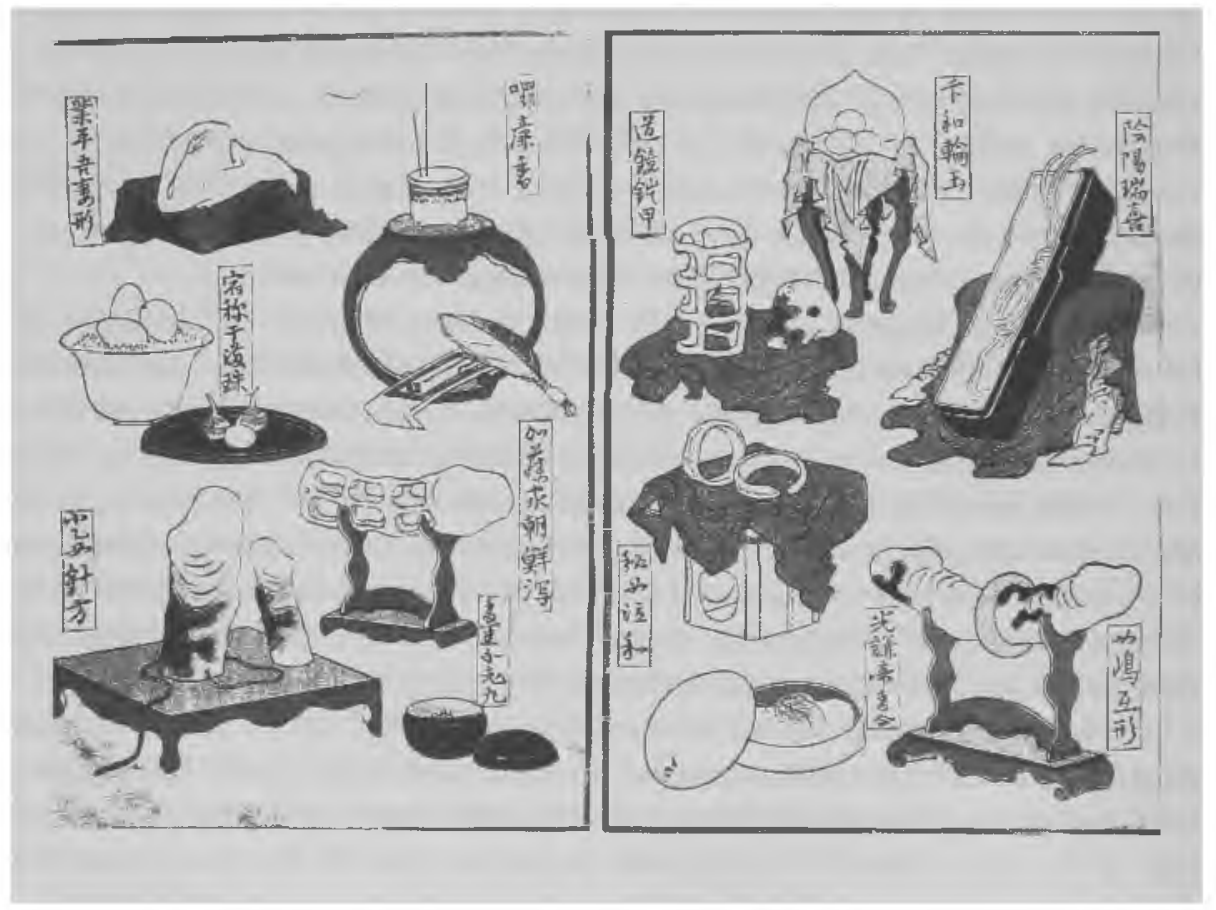

3. In Fukuda Kazuhiko, Enshoku ukiyo zensh $\hat{u}$, vol. 6 Hokusai, pp. 50 e 186. 
A imagem traz, didaticamente, as referências nominais de cada objeto e aqui passamos a discriminá-los enquanto origem e finalidade.

Do lado esquerdo, leiam-se:

「囉策香」Rarenkô, "aroma de cortinado holandês": incenso afrodisíaco trazido da Holanda com o qual os desejos se acenderiam.

「加藤家朝鮮潟」Katôke chôsengata, "consolo coreano da casa Katô": consolo que, segundo consta, foi trazido por Katô Kiyomasa da Coréia, quando Toyotomi Hideyoshi fez para lá sua excursão bélica, no século XVI; geralmente feito de casco de tartaruga, era aconselhado especialmente para os velhos.

「香閏不老丸」Kôkei furôgan, "pílula perfumada anti-envelhecimento", um dos tipos de pastilhas afrodisíacos cujo aroma, à maneira da fumaça de Rarenkô, incitaria fortemente ao sexo.

「業平吾妻形」Narihira azumagata, "forma do país do leste de Narihira", objeto para masturbação masculina; trata-se de um saco em forma de vagina no qual se introduz o pênis, tendo-se aquecido ou a própria pele ou o tecido do invólucro; o lado externo era de veludo ou de seda, sendo o interno de couro.

「宿襧千満珠」Sukune senmanju, "magnífica bola de mil satisfações de Sukune", alimento consistente em ovos e bulbos de planta japonesa sempre-verde, kuwai 慈姑 (Sagittaria trifolia), apreciado como doadores de longevidade e juventude eterna, em alusão à lenda que consta em Kojiki e Nihonshoki (Takenouchino Sukune rouba a pílula da longevidade e das mil satisfações do palácio das princesas aquáticas).

「小乙女針方」Otome harigata, "consolo fino da pequena moça": o modelo maior é para ser amarrado no calcanhar e manipulado conforme os movimentos dos pés, enquanto que o menor é para ser colocado no dedo; ambos são feitos de casco de tartaruga (note-se a grafia diferente de harigata, utilizando-se o ideograma para "agulha", denotando "delgado, fino" pois para virgens).

Do lado direito, ieiam-se:

「卡和輸玉」Benkano rinnotama, "bolas rin de Benka"; Benka é personagem da história antiga chinesa da era dos reinos da Primavera e do Outono, célebre por ter cavado pedras preciosas, as ditas rinnotama, que podem ser grafadas com ideogramas diferentes (輪の玉 "bola de corola de flor”, 琳の玉, "bola que emite som"). Utilizadas desde a antigüidade até hoje para realçar o prazer das mulheres, são feitas de metal, e o conjunto se compõe de três, sendo que duas delas são colocadas no fundo da vagina e, conforme se vai atingindo o clímax, o balançar dos quadris faz facilmente atingir o orgasmo. Como as bolas se chocam com o movimento, produz-se um som metálico, sendo também chamadas de suzunotama 鈴の玉 ("bola de sino").

「光謙帝香合」Kôkentei kôgô, "perfume de Kôkentei": conhecidas como mulheres belíssimas e sem par neste mundo, Dôkyô e Kôkentei são célebres; o incenso é dito ter sido moldado nas partes íntimas de Kôkentei. 
「陰陽瑞喜」In yô zuiki, “feliz gratidão a yin e yang” e「秘女泣和」 Hime nakiwa, "anel que faz chorar em segredo e harmonia as donzelas" (姫泣輪), são ambas para serem utilizadas no pênis: as cordas zuiki são amarradas em toda a sua extensão, os anéis são colocados ou sob o prepúcio ou em sua base, devendo serem aquecidas antes do uso. Diz-se serem altamente eficientes para aumentar o prazer das mulheres.

「道鏡鎧甲」Dôkyô yoroi kabuto, "elmo e armadura de espelho taoista", ambos feitos de casco de tartaruga, o elmo é utilizado sobre o prepúcio e a armadura sobre o corpo do pênis. $\mathrm{O}$ objeto é recomendado para os de pênis muito fino.

「女嶋互形」Nyôgogashima tagaigata, "consolo mútuo da Ilha das Mulheres", idêntico ao oribós da antiga Grécia, é destinado ao uso simultâneo e mútuo de duas mulheres. Feito de casco de tartaruga, o objeto deve ser aquecido antes do uso, inserindo-se nele ou água quente ou tecido nela embebido.

Nota-se que, ao se visitar qualquer site contemporâneo sobre o tema, ou se visitar algum sex shop, tais instrumentos estarão ainda presentes em forma modernizada de macio látex, aquecidos, mecanizados, eletrizados, perfumados, coloridos.

Na obra Tokono okimono 床の置物, “Omamentos do leito”, de Hishikawa Moronobu 菱川師宣, produzido entre 1681 a 1684, em um volume de xilogravuras preto-e-branco, os dildos encontram lugar privilegiado.

Diz o seu prefácio:

凡交遊のしなある事は一生うれへをさつてはよろこびを延べ し、寝䇥のう总にも話の真砂の数々つくる事なし、往古作蔵 と云ふ色ごのみあり、妻別れをかなしみければ、をのが一物 を木像に作りカタミにあたへしを 逢ふ心地して寵愛のあま りに名付て作蔵と云しを、末世の人木蔵古風なりとて生る一 物をなべて作蔵と云、己が知徳を生まれながらにして是をし り 習子て是をする、其是をする事皆一つ成と孔子もつくさ れたれば、稽古のためになれとて床の置物と名を付るのみ。

Existe um objeto que, mesmo que passe uma vida de sofrimentos, tem a qualidade do companheirismo e prolonga a alegria, que não deixa ocasião para que nem pequenos grãos de areia incomodem as conversas no leito quando nos encontramos sobre seus acolchoados. Havia um grande amante do amor que se chamava desde antigamente Sakuzô e, triste por ter de se separar da esposa, fez uma estátua de madeira de seu próprio pênis e a colocou numa caixinha de bambu; ela, tomada de grande afeto e ansiando por encontrarem-se, deulhe o nome do marido, Sakuzô e, desde então, as pessoas passaram a chamar Sakuzô as imitações de pênis feitas de madeira, que já existiam desde há muito. Desde que tenho algum discernimento, 
conheço este fato; depois de aprender [como usá-lo], pratico; e, como Confúcio também mandou fazer um dizendo: "em primeiro lugar, é necessário aprender a fazer assim e assado", e deu-lhe o nome de "ornamento do leito", ordenando-lhe que servisse para praticar.

O nome da personagem Sakuzô 作蔵, grafado com outro ideograma, 作像 "estátua feita", passa a ser linguagem cifrada para o membro masculino, em trocadilho com o material com que fora feito, 木像 “estátua de madeira", tendo supostamente se originado neste texto, conforme referem muitas narrativas do gênero ukiyozôshi. A retórica da persuasão invoca o venerável nome de Confúcio, como sói ocorrer em muitas narrativas dos citadinos.

Analisaremos aqui quatro imagens deste álbum.

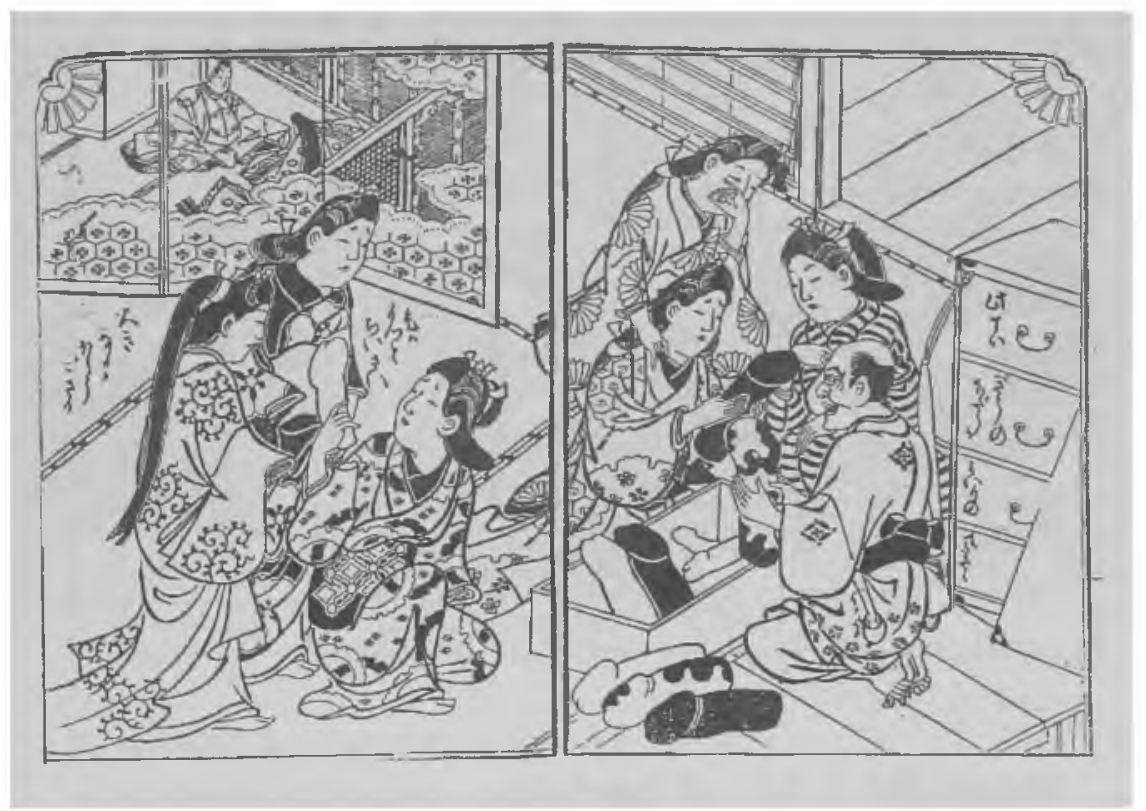

Comerciante: 此すいぎう（水牛）のまだらがよいものでごさらふ - Vede aqui, como este é um artigo superior, feito de búfalo de lindas manchas!

Dama: 是はもつとちいさい、大きなのがほしうごさる - Este aqui é muito pequeno, desejaria um bem maior...

A imagem apresenta a varanda e a antecâmara aos aposentos femininos talvez de uma residência de xogum ou daimio, notável pelo vestuário e refinamento - notese a pintura que representa cortesãos do período Heian. O comerciante, qual caixeiro 
viajante, carrega sua mala nas costas e de uma das gavetas extrai uma variedade de enormes consolos, aqui aumentados para obedecer à retórica do "mais importante, maior" qual hibérbole visual.

Tanaka também aponta a já propalada retórica do exagero nas proporções na representação dos órgãos sexuais na pintura shunga, que, é claro, não deve ser tomada literalmente - o especialista em estampas ukiyoe Fukuda Kazuhiko chamou o método de "deforumé", ou "deformação" Em termos de representação visual, a hipérbole é bem vinda, entretanto, na sensibilidade dos citadinos, um aspecto de "charme e inteligência" [share 酒落], quando exagerado demais, torna-se o seu oposto, "caipira ou tosco" [yabo 野暮].

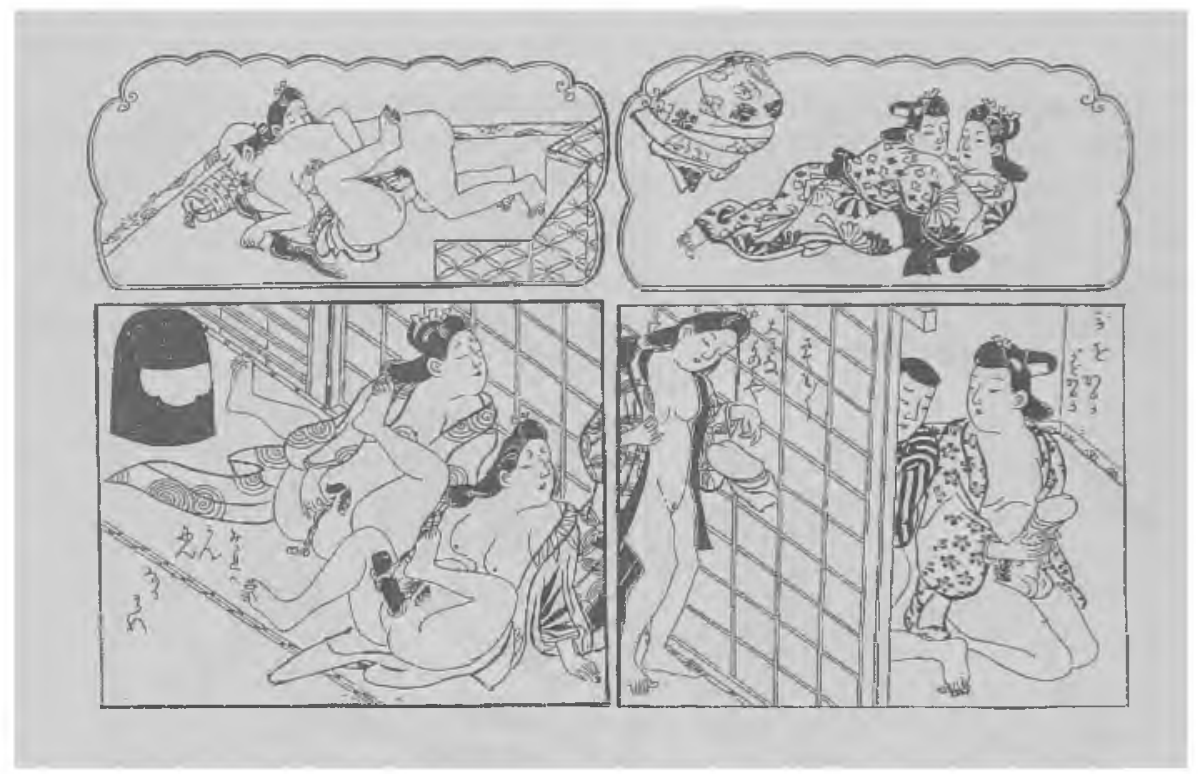

Homem: 我をおろか、我をおろか

- Me faz de tonto! Me faz de tonto!

Mulher de pé: さても | | おきなものじゃ

- Nossa, nossa! Que coisa grande!

Mulher recostada: それはかんにんなるまい

- Ah, como é que dá para agüentar isso?

Parte da retórica das estampas eróticas apresenta cenas como essa, do gênero "atravessando a porta corrediça" [shôjigoshi 障子越 L], imagem até compreensível, por ser ela composta de esquadrias de madeira e forrada de papel. Mas também pode aparecer como "atravessando paredes" [kabegoshi 壁越 L], 
que mostra uma potência que atravessa até a madeira; ou como "escondido entre as persianas" [sunokokakure 策子隠れ], voyeurismo já famoso nas Narrativas de Genji e Narrativas de Ise.

Aponta Tanaka que os homens provavelmente pertencem a uma baixa categoria, talvez de peixeiros ou verdureiros que vinham fazer entregas, e empregadas da casa. Com efeito, cenas com estes trabalhadores abundam nas estampas shunga, e nos fazem pensar em entregadores de pizza e personal trainers contemporâneos.

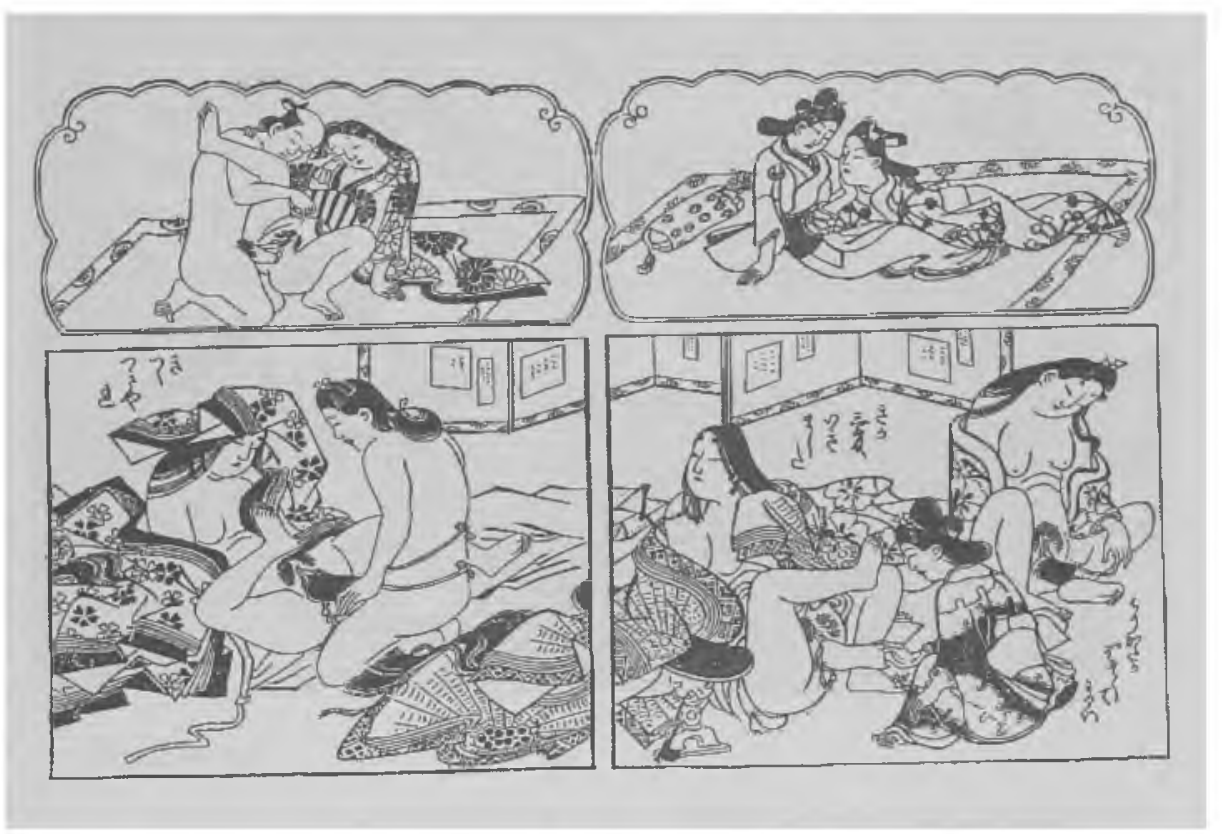

Lado direito inferior: はりがたがほそくてわるい

- Este consolo é ruim, pois é muito fino.

Lado direito superior: 気が三度いきました

- Ah, já fui três vezes!

Lado esquerdo: きつくつきやれ

- Enfia ele forte, até o fim!

A estampa segue a mesma estrutura que a anterior, comum no livro todo, com duas pequenas cenas de sexo a dois, homem e mulher, e na parte de baixo, as mulheres a se entreterem de formas diversas, como a dizer: "na falta de..."

No aposento feminino [nyokan, nyôkan, jokan 女官], mulheres de alta $\mathrm{e}$ média categoria, com auxílio de suas atendentes, se divertem desbragadamente. 
Aponta Tanaka o poder imaginativo da época, em relação a mulheres aos homens comuns interditas, e também o caráter coletivo que tal tipo de entretenimento teria tido, ou, por outro lado, a falta de privacidade para $o$ ato. Por outro lado, atesta a fato do hábito do que chama de "dormir como um monte de peixes amontoados" [sagone 雑魚寝], comum desde a antigüidade.

Vemos três modos diferentes de utilização do consolo: sozinha, com o auxílio do próprio calcanhar, amarrado à cintura de uma atendente que imita o ato a dois, auxiliada manualmente por outrem.

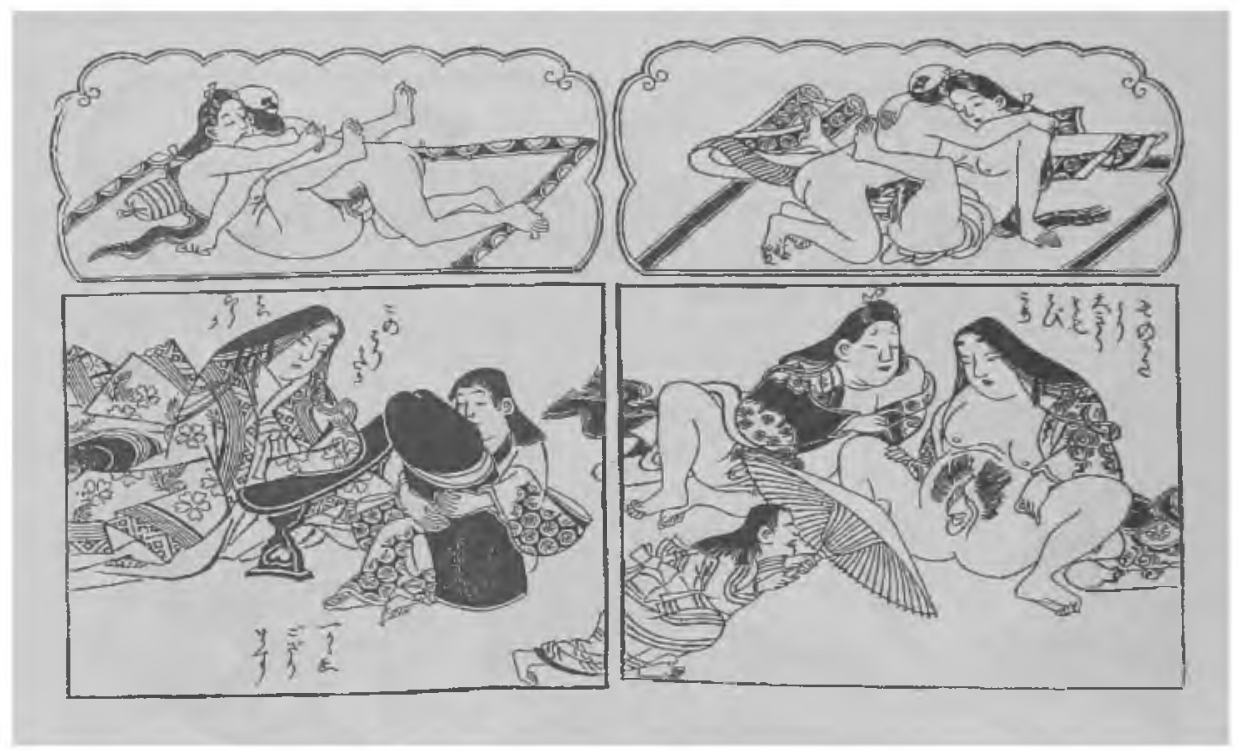

Lado direito: そのかさより大きくともとびこめ

- Rasga-me de vez, com este grande guarda-sol!

Lado esquerdo: 一かか总ござります

- Ah, estou carregando um!

Lado esquerdo: このはりかたがはいらうか

Será que este consolo vai entrar?

A comicidade desta imagem é óbvia: entre as cortesãs, a aprendiz menina [kamuro 秀] encena uma penetração impossível; do lado esquerdo, a proporção hiperbólica não deixa dúvidas quanto à intenção do pintor, de uma obviedade gritante. Porém, tal imaginação tem suas raízes na literatura, e Tanaka refere um dos contos de Ihara Saikaku em Histórias das provincias (Shokokubanashi 諸国ばなし), na qual um Deus Guarda-Chuva se enreda com uma viúva. Um consolo pode, portanto, ter outras formas, sendo muito conhecidas as metáforas de vegetais. 
Passaremos, de modo abrupto, a uma análise de duas estampas multicoloridas produzidas mais de um século depois. Uma série de 12 estampas em folha solta, sem título, publicada em 1801 e atribuída à escola de Kitagawa Utamaro mostra uma cena em que não se trata propriamente de um consolo, embora a função a ele atribuída seja a mesma. Chôkyôsai Eiri também assina uma estampa praticamente igual, e está inserida no álbum de 12 estampas multicoloridas em grandes dimensões, "Cartas Alegres de Belas Esposas" [Fumino Kyogaki 婦美の清書].

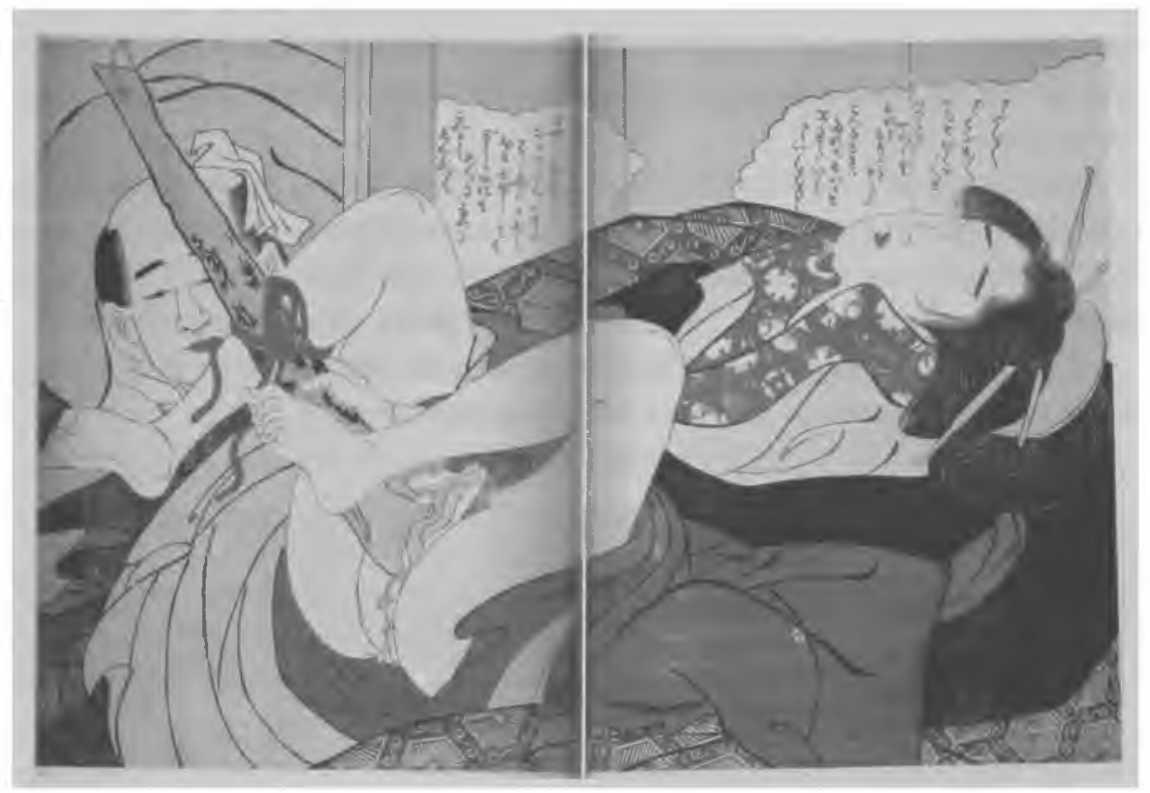

Diz o texto:

$$
\text { アロいく||。ア、どふも||。まつとおくを|｜とい }
$$
つても、やつぱりおれとすりこぎが斗りだ。こんなときは、

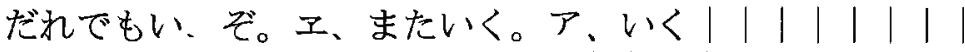
なだかそう||しい。ひちゃ｜｜｜とろ、でも 寸るやうな。大かた、おか（岡場所）のさへがまたはじめた か。あらほどとぼしても。どうかおれもあじになつた。これ からしんぐい|。

$\mathrm{Ah}$ ! Ah! Eu vou, eu vou. Ah! Ah! É muito, é muito!" Por mais que eu diga: no fundo, no fundo, realmente, somos somente eu e o pilão de madeira... Nessas horas, qualquer um seria bom! Weh! Weh! Vou de novo. Ah! Ah! Vou, vou, vou, vou, vou!

4. In Coleção Ukiyoe "Shunga Meihin Shûsei - Eiri" "Fumino Kyogaki" (Obras-primas do Ukiyoe Erótico Eiri), vol.9, Hayashi Yoshikazu e Richard Lane, pp.14-15. 
Parece mesmo que foi... Como se estivesse ralando quiabo: hicha hicha hicha! Ih, A vulva da Sae da clandestina área de prazeres começou de novo? E como se incendeia! Ah, também fiquei sentindo o gostinho... A partir de agora, mais uma vez e outra vez!

Tanaka aponta a metáfora comum no período Edo, particularmente em sua segunda metade: o pilão de madeira, para o membro masculino; o almofariz, para o membro feminino. A figura refere a mulher como pertencente ao universo da prostituição não legalizada, uma "livre empresária" do sexo, que, embora profira o discurso de que "qualquer homem seria suficiente", mostra desprezar o cliente yabo que, estupefato, a observa.

Fazendo as vezes de "médico" (ishamitate 医者見立て), como o fez em uma série de obras sobre as estampas do travesseiro o médico e pesquisador de shunga Tanobe Tomizô, notamos na imensa vagina provir um fluxo enorme de "sêmen" feminino o termo insui 淫水, "líquido seminal” já era utilizado para ambos.

Também da mesma série, uma célebre imagem (no início, atribuída à escola de Utamaro), mostra-se duas mulheres em jogos amorosos ${ }^{5}$

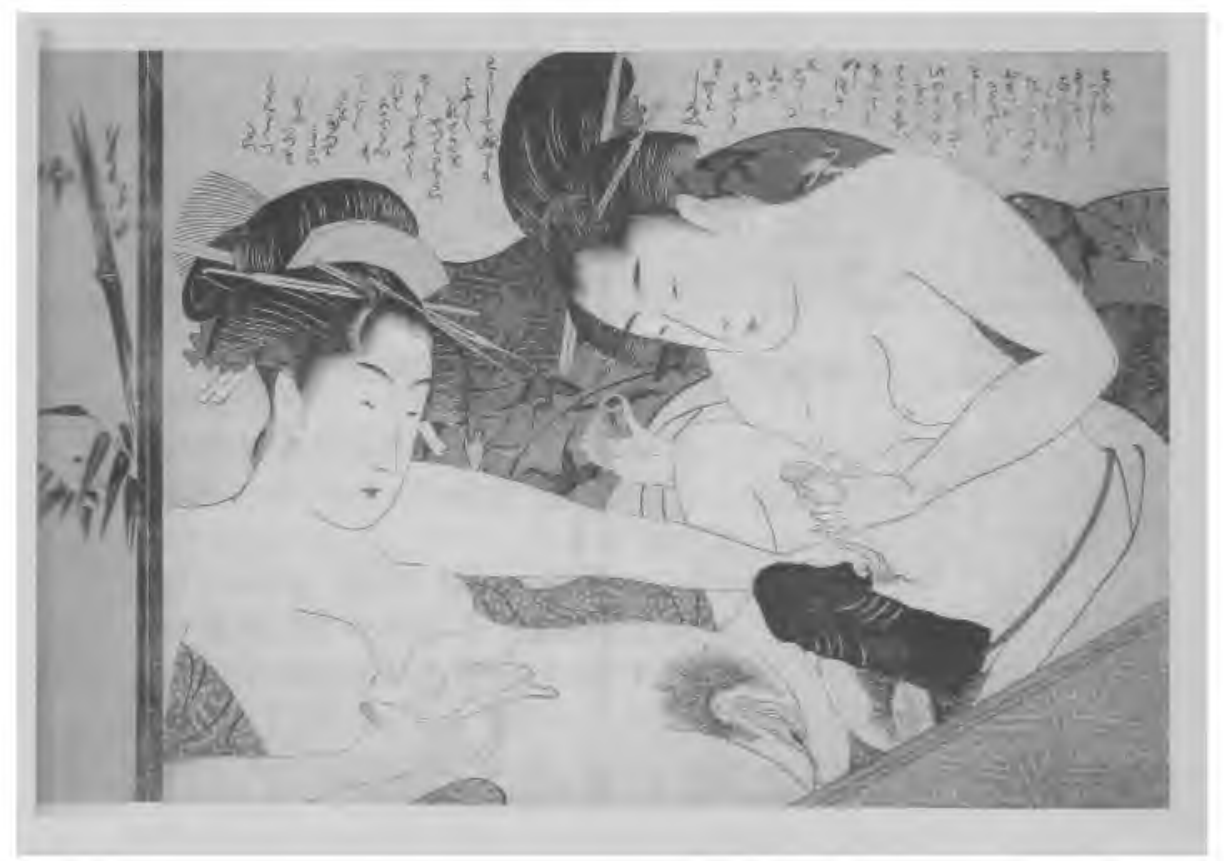

5. In UHLENBECK Chris \& WINKEL Margarita, Japanese Erotic Fantasies - Sexual Imagery of the Edo Period. Holanda, Hotei, 2005, p.147. 
どうでこうしてするからは、なんでも此のくすりをたんとつ けて、おもいれに気をやんあ。そうでなくつては、此の大き なものがはいらない。なんてもぬらつきで大こしにしてあげ やう。工、せわしない

Como é que pode? Só de passar direitinho este remédio, a gente fica com uma vontade! Se não fosse deste jeito, este negócio monstruoso não caberia. Posso passar em qualquer coisa e dar nas suas coxonas. Weh, weh, não apressa!

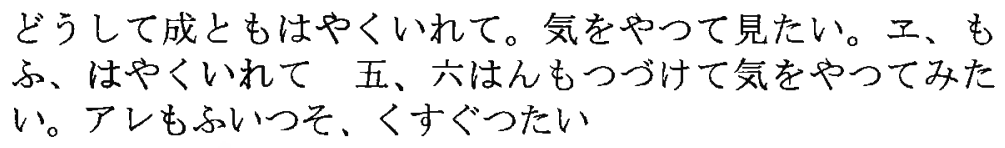

"Por que a demora? Coloca logo! Quero experimentar a sensação. Weh, weh, já, coloca logo, estou com vontade de dar uma cinco ou seis vezes em seguida. Ai, ai, anda logo com isso, que formigamento!"

Atenta Tanaka que, embora esta cena se assemelhe a uma situação lésbica, o fato de utilizarem o consolo como substituto do órgão masculino, na verdade, revela o olhar e a sensibilidade dos homens, ou seja, a de que eles seriam cânone imprescindível nesta relação. A relação entre as mulheres, jocosamente referida como autofagia [tomogui 共食い], embora com outros ideogramas a significar "brincadeira e encontros" [合淫], ou "competição de conchas" [kaiawase 買合せ] não encontra sucedâneo em "amor romântico" ou "amor idealizado" como o ocorrido entre os homens.

Ainda citando Tanaka, para a fantasia masculina do período Edo, embora ambos os sexos se masturbassem, a mulher necessitaria de instrumentos auxiliares, ao passo que os homens se centralizariam em espiar, ver, ouvir. As estampas ukiyoe, escreve em seu posfácio de 2004 , podem ser estudadas não somente do ponto de vista estético e histórico, enquanto gênero artístico, mas também servem de material prolífico para a história da vida privada, a história das mulheres, estudos da cultura em geral. Em especial, serve à história da sexualidade, enquanto prática e concepção. Sua reflexão muito deve a uma nova apreciação que das estampas têm feito Hayakawa Monta e Shirakura Yoshihiko, com estudos monográficos, recortes temáticos e, principalmente, leituras e interpretações dos textos que acompanham os livros e estampas eróticas.

Uma das discussões mais freqüentes ao se lidar com este gênero diz respeito a que, segundo o ponto de vista feminista, "as estampas eróticas e a pornografia representam imagens de mulheres do ponto de vista do olhar dos homens" e, portanto, 
a conclusão seria a de que "o que se encontra representado não é realidade e não passa do desejo dos homens" Entretanto, argumenta Tanaka que, embora mais da metade [quase a totalidade, nos parece] dos pintores tenha sido do sexo masculino, a representação do shunga ukiyoe, diferentemente das produções pornográficas modernas, apresenta casais em atividade equilibrada. Tal característica deve se ligar ao que lendariamente se dizia: que eram produzidas para fazer parte do enxoval de moças, ou para acompanhar os homens em suas guerras e matanças, ou para evitar os males e as doenças ou, afastando-se no tempo, para venerar os deuses da natureza e a longevidade taoista. As imagens shunga não se destinam, pois, somente a olhos masculinos, como podemos ler nas obras de Ihara Saikaku. E não representam somente os desejos de homens, como podemos notar na sutileza da expressão feminina.

Outro aspecto fundamental, já lembrado por Hayashi, Hayakawa, Fukuda, Shirakawa e outros, é o seu aspecto risível, gracioso, bem humorado, perspicaz. Embora existam algumas cenas de estupro e violência, o gozo até aí se encontra presente.

\section{Bibliografia sucinta}

FAGIOLI Marco, Shunga The Erotic Art of Japan. Nova York, Universe \& Rizzoli, 1998.

FUKUDA Kazuhiko 福田和彦. Enshoku Ukiyoe Zenshû唈色浮世絵全集 (Enciclopédia da Pintura Ukiyoe Erótica). Tóquio, Ed. Kawade, 10 volumes, 2006 (1 ${ }^{\mathrm{a}}$. Ed.: 2003).

HAYASHI Yoshikazu 林美一 \& LANE Richard. Ukiyoe Shunga Meihin Shûsei 9: Chôkyôsai Eiri “Fumino Kyogaki 浮世絵春画名品集成9鳥橋際栄里「婦美の着書」 (Coleção Obras-Primas do Ukiyoe Erótico vol. 9: "Cartas Alegres de Belas Esposas" de Chôkyôsai Eiri). Toóquio, Kawade, 1996.

TANAKA Yuko 田中優子: Harigata to Edo Onna 張形と江戸をんな (O Consolo e a Mulher no Período Edo). Tóquio, Yôsensha, 2004.

TANOBE Tomizô 田野辺富蔵. Ishamitate Eisen “Makura Bunko” 医者見立て 栄泉「枕文庫」 (Posando de Médico: "Enciclopédia do Sexo" de Eisen). Tóquio, Kawade, 1966.

UHLENBECK Chris \& WINKEL Margarita. Japanese Erotic Fantasies - Sexual Imagery of the Edo Period. Roterdã, Hotei, 2005. 